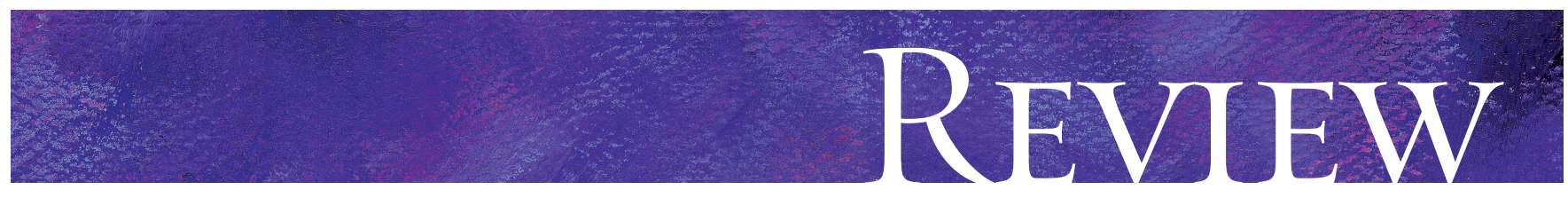

\title{
Epigenetics and human disease: translating basic biology into clinical applications
}

\author{
David Rodenhiser, Mellissa Mann
}

\section{ABSTRACT}

Epigenetics refers to the study of heritable changes in gene expression that occur without a change in DNA sequence. Research has shown that epigenetic mechanisms provide an "extra" layer of transcriptional control that regulates how genes are expressed. These mechanisms are critical components in the normal development and growth of cells. Epigenetic abnormalities have been found to be causative factors in cancer, genetic disorders and pediatric syndromes as well as contributing factors in autoimmune diseases and aging. In this review, we examine the basic principles of epigenetic mechanisms and their contribution to human health as well as the clinical consequences of epigenetic errors. In addition, we address the use of epigenetic pathways in new approaches to diagnosis and targeted treatments across the clinical spectrum.

CMAJ 2006;174(3):34I-8

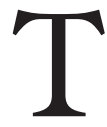
he field of genetics has become an integral part of modern medicine in the 50 years since Watson and Crick described their structural model of DNA. In this time, significant advances have been made in identifying specific mutations associated with such human diseases as Huntington's chorea and cystic fibrosis. Further advances, including the Human Genome Project, are providing new opportunities to develop better diagnostic tools and targeted gene therapies.

A new field that will also have an enormous impact on medicine is epigenetics. It is the study of heritable changes in gene function that do not change the DNA sequence but, rather, provide an "extra" layer of transcriptional control that regulates how genes are expressed. ${ }^{1}$ This rapidly evolving field offers exciting new opportunities for the diagnosis and treatment of complex clinical disorders. In this review, we will provide clinicians with an understanding of the principles of epigenetic mechanisms and how these principles relate to human health and disease. We will also address the use of epigenetic pathways in new approaches to molecular diagnosis and novel targeted treatments across the clinical spectrum.

\section{Basic principles of epigenetics: DNA methylation and histone modifications}

The human genome contains 23000 genes that must be expressed in specific cells at precise times. Cells manage gene expression by wrapping DNA around clusters (octamers) of globular histone proteins to form nucleosomes (Fig. IA). ${ }^{2}$ These nucleosomes of DNA and histones are organized into chromatin. Changes to the structure of chromatin influence gene expression: genes are inactivated (switched off) when the chromatin is condensed (silent), and they are expressed (switched on) when chromatin is open (active) (Fig. IB). ${ }^{3}$ These dynamic chromatin states are controlled by reversible epigenetic patterns of DNA methylation and histone modifications. ${ }^{4}$ Enzymes involved in this process include DNA methyltransferases (DNMTs), histone deacetylases (HDACs), histone acetylases, histone methyltransferases and the methyl-binding domain protein MECP2. Alterations in these normal epigenetic patterns can deregulate patterns of gene expression, which results in profound and diverse clinical outcomes.

The loss of normal DNA methylation patterns is the best understood epigenetic cause of disease, based on the initial studies during the I980s that focused on $\mathrm{X}$ chromosome inactivation, ${ }^{5}$ genomic imprinting ${ }^{6}$ and cancer. ${ }^{4}$ DNA methylation involves the addition of a methyl group to cytosines within $\mathrm{CpG}$ (cytosine/guanine) pairs ${ }^{7,8}$ (Fig. IA). Typically, unmethylated clusters of $\mathrm{CpG}$ pairs are located in tissuespecific genes and in essential "housekeeping" genes, which are involved in routine maintenance roles and are expressed in most tissues. These clusters, or CpG "islands," are targets for proteins that bind to unmethylated $\mathrm{CpGs}$ and initiate gene transcription. In contrast, methylated $\mathrm{CpGs}$ are generally associated with silent DNA, can block methylationsensitive proteins and can be easily mutated. DNA methylation patterns are established and maintained by DNMTs, enzymes that are essential for proper gene expression patterns. ${ }^{9}$ In animal experiments, the removal of genes that encode DNMTs is lethal; in humans, overexpression of these enzymes has been linked to a variety of cancers.

In addition to DNA methylation, changes to histone proteins orchestrate DNA organization and gene expression. ${ }^{2} \mathrm{Hi}-$ stone-modifying enzymes are recruited to ensure that a recep- 
tive DNA region is either accessible for transcription or that DNA is targeted for silencing ${ }^{10-12}$ (Fig. IB). Active regions of chromatin have unmethylated DNA and have high levels of acetylated histones, whereas inactive regions of chromatin contain methylated DNA and deacetylated histones. ${ }^{2}$ Thus, an epigenetic "tag" is placed on targeted DNA, marking it with a special status that specifically activates or silences genes. These reversible modifications ensure that specific genes can be expressed or silenced depending on specific developmental or biochemical cues, such as changes in hormone levels, dietary components or drug exposures. ${ }^{11,13}$

\section{Nature or nurture ... or both?}

DNA methylation patterns fluctuate in response to changes in diet, inherited genetic polymorphisms and exposures to envi-

A

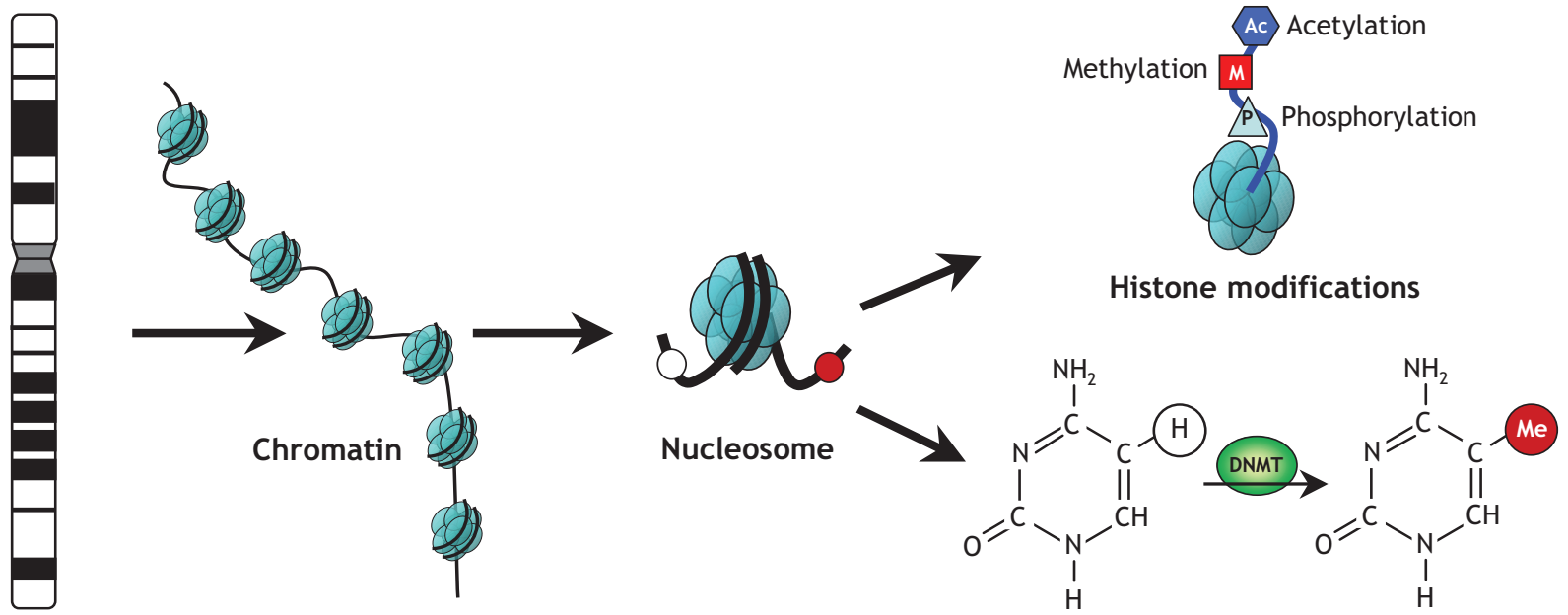

Chromosome

DNA methylation

B

Gene "switched on"

- Active (open) chromatin

- Unmethylated cytosines (white circles)

- Acetylated histones

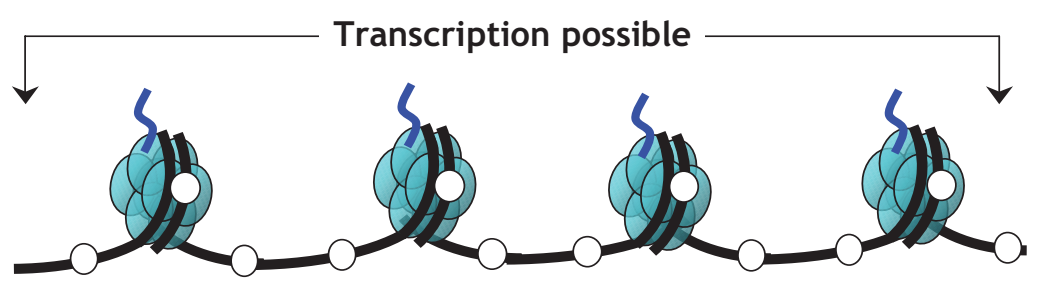

$\downarrow \uparrow$

Gene "switched off"

- Silent (condensed) chromatin

- Methylated cytosines (red circles)

- Deacetylated histones

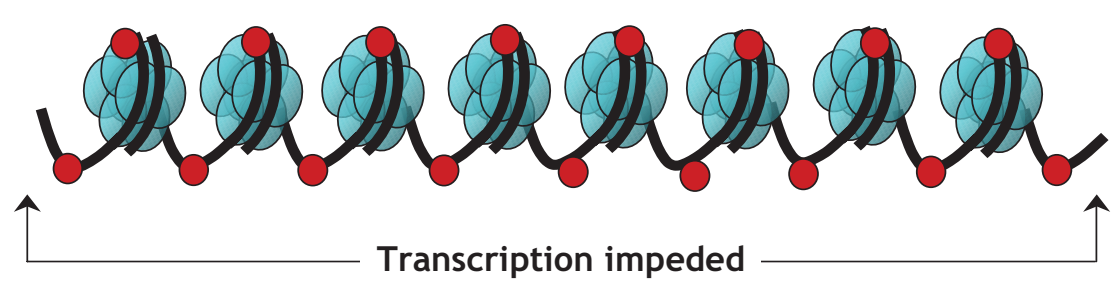

Fig 1: (A) Schematic of epigenetic modifications. Strands of DNA are wrapped around histone octamers, forming nucleosomes. These nucleosomes are organized into chromatin, the building block of a chromosome. Reversible and site-specific histone modifications occur at multiple sites through acetylation, methylation and phosphorylation. DNA methylation occurs at 5-position of cytosine residues in a reaction catalyzed by DNA methyltransferases (DNMTs). Together, these modifications provide a unique epigenetic signature that regulates chromatin organization and gene expression. (B) Schematic of the reversible changes in chromatin organization that influence gene expression: genes are expressed (switched on) when the chromatin is open (active), and they are inactivated (switched off) when the chromatin is condensed (silent). ${ }^{3}$ White circles = unmethylated cytosines; red circles = methylated cytosines. 
ronmental chemicals. ${ }^{14,15}$ Methyl groups are acquired through the diet and are donated to DNA through the folate and methionine pathways. ${ }^{16}$ Changes in DNA methylation may occur as a result of low dietary levels of folate, methionine or selenium, which can have profound clinical consequences such as neural tube defects, cancer and atherosclerosis. ${ }^{17-21}$ Such imbalances in dietary nutrients can lead to hypomethylation (which contributes to improper gene expression) and genetic instability (chromosome rearrangements). ${ }^{21}$ For example, hyperhomocysteinemia and global hypomethylation have been observed in vitro in atherosclerosis models, which supports an emerging view that alterations in global methylation patterns are characteristic of early stages of this disease. ${ }^{19}$ In advanced stages of atherosclerosis, hyperproliferation may further contribute to DNA hypomethylation and altered gene expression. ${ }^{22}$

Environmental agents such as metals (e.g., arsenic) and aromatic hydrocarbons (e.g., benzopyrene) can also destabilize the genome or modify cellular metabolism, or both. ${ }^{22,23}$ These environmental contaminants are found in occupational chemicals, fossil fuel emissions, contaminated drinking water and cigarette smoke. ${ }^{14}$ People's sensitivity to diet or to environmental toxins may vary owing to preexisting genetic variants that can challenge methyl metabolism and predispose a person to epigenetic change. Some reports have linked a common polymorphism in the methylenetetrahydrofolate reductase (MTHFR) gene to altered DNA methylation patterns in response to diet, alcohol consumption and hormone replacement and an apparent increased incidence of breast and colorectal cancer in certain populations. For example, the common MTHFR 677 CT polymorphism has been shown to increase the risk of breast cancer up to 3 -fold in premenopausal women. ${ }^{24,25}$ Other studies suggest that the 677 TT genotype confers a $40 \%$ decreased risk of breast cancer, particularly in postmenopausal women using hormone replacement therapy, by limiting the availability of nucleic acid precursors required by hyperproliferating cells. ${ }^{26}$ Such examples underscore the complex interplay between epigenetics, the environment (nurture) and genetic individuality (nature) that potentially increase the risk of epigenetic disease.

\section{Clinical consequences of epigenetic errors}

Epigenetic mechanisms regulate DNA accessibility throughout a person's lifetime. Immediately following fertilization, the paternal genome undergoes rapid DNA demethylation and histone modifications. ${ }^{27}$ The maternal genome is demethylated gradually, and eventually a new wave of embryonic methylation is initiated that establishes the blueprint for the tissues of the developing embryo. As a result, each cell has its own epigenetic pattern that must be carefully maintained to regulate proper gene expression. Perturbations in these carefully arranged patterns of DNA methylation and histone modifications can lead to congenital disorders and multisystem pediatric syndromes or predispose people to acquired disease states such as sporadic cancers and neurodegenerative disorders (Box I).
Box 1: Normal cellular functions regulated in part by epigenetic mechanisms and molecular abnormalities caused by epigenetic errors

\section{Normal functions}

- Correct organization of chromatin

- Specific DNA methylation and histone modifications

- Silencing repetitive elements

- Genomic imprinting

- X chromosome inactivation

Controls active and inactive states of embryonic and somatic cells

Controls gene- and tissuespecific epigenetic patterns

Ensures that chromatin order and proper gene expression patterns are maintained

Is essential for development

Balances gene expression between males and females

Abnormalities

- DNA hypermethylation

- DNA hypomethylation

- Mutations at methylated cytosines

- Imprinting defects

Results in chromatin condensation and silencing of tumour suppressor and other genes

Activates oncogenes, results in chromosomal instability, activates transposons

Results in inappropriate gene expression

Results in loss of parental identity

\section{Genomic imprinting and imprinting disorders}

Genomic imprinting allows genes to "remember" whether they were inherited from the mother or the father so that only the maternally or paternally inherited allele is expressed. Imprinting is regulated by DNA methylation and histone modifications $^{6}$ and is important in the context of a variety of developmental and pediatric disorders ${ }^{54-58}$ (Table I).

Prader-Willi, Angelman and Beckwith-Weidemann syndromes best characterize congenital imprinting disorders. ${ }^{54,55}$ Prader-Willi and Angelman syndromes are caused by genetic and epigenetic errors to the same part of chromosome 15; errors inherited from the father result in Prader-Willi syndrome, and those inherited from the mother, Angelman syndrome. ${ }^{54}$ Beckwith-Wiedemann syndrome is caused by genetic or epigenetic mutations resulting in loss of imprinting on chromosome II. $^{55}$

Besides gene-specific imprinting effects, global imprinting changes can occur in embryos that completely lack one parental genome (Table I). For example, spontaneous activation of oocytes in situ leads to ovarian teratomas that lack a paternal genome. ${ }^{64}$ In contrast, complete hydatidiform moles have been found that lack a maternal genome and an embryo and exhibit hyperproliferation of trophectoderm tissues, with the potential of forming choriocarcinoma. ${ }^{65}$ The recessive disorder "familial biparental complete hydatidiform mole" also leads to recurrent development of moles when maternalspecific imprints fail to be established during oogenesis ${ }^{67}$ Interestingly, imprinting effects that appear to target trophoblast cells have been recently implicated as a cause of preeclampsia. ${ }^{68}$ 


\section{Assisted reproductive technology}

Recent evidence suggests that the manipulation of embryos for the purposes of assisted reproduction or cloning may impose inherent risks to normal development. For example, assisted reproductive technologies (ARTs) have been linked to an increased risk of intrauterine growth retardation (odds ratio [OR] I.59, 95\% confidence interval [CI] I.20-2.II), premature birth (< 33 weeks' gestation, OR 2.99, 95\% CI I.54-5.80; < 37 weeks' gestation, OR I.93, 95\% CI I.36-2.74), low birth weight (< $1500 \mathrm{~g}$, OR $3.78,95 \% \mathrm{CI} 4.29-5.75)$ and prenatal death (OR 2.40, 95\% CI I.59-3.63). ${ }^{69,70}$ Furthermore, an apparent association with ARTs was recently found in registries of children with Angelman syndrome and BeckwithWiedemann syndrome. ${ }^{71}$ The prevalence of ART use was about 4-9 times greater among children with BeckwithWiedemann syndrome than among children in the general population (OR $\geq 3.2,95 \% \mathrm{CI}$ I.4-7.3). Molecular analyses of patients with Angelman syndrome and Beckwith-Wiedemann syndrome conceived by in vitro fertilization or intracytoplasmic sperm injection revealed a loss of maternal-specific DNA methylation at imprinting centres, which indicates that the errors were epigenetic in nature. Although individually rare, as a group, epigenetic errors may impose significant risk for people conceived by ART. Similarly, in vitro culture in animal models has been found to lead to reduced viability and growth, developmental abnormalities, behavioural changes and loss of imprinting. ${ }^{72,73}$ Such reports suggest that technologies involving the manipulation of cultured embryos may be the "tip of the iceberg" for a wider spectrum of epigenetic alterations. ${ }^{74}$ Further study is required to determine whether epigenetic changes give rise to other imprinting disorders (or to cancer), and why such viability and growth defects appear to occur at increased frequency in the ART population.

Table 1: Associations between epigenetic modifications and human diseases and conditions

\begin{tabular}{|c|c|c|c|c|c|}
\hline Disease/condition & Gene & Biological process & Disease/condition & Gene & Biological process \\
\hline Cancer & & & Neurologic & & \\
\hline Bladder & Multiple genes & Hypermethylation ${ }^{20}$ & Schizophrenia & RELN & Hypermethylation ${ }^{46,47}$ \\
\hline Brain (glioma) & RASSF1A & Hypermethylation ${ }^{28,29}$ & Bipolar disorder & $11 p ?$ & Unknown $^{48}$ \\
\hline Brain (glioblast) & MGMT & Hypermethylation ${ }^{30}$ & Memory formation & Multiple genes & Hypo-, hypermethylation ${ }^{49}$ \\
\hline Breast & BRCA1 & Hypermethylation ${ }^{31}$ & Lupus & Retroviral DNA & Hypomethylation ${ }^{50}$ \\
\hline Cervix & p16 & Hypermethylation ${ }^{34}$ & Atherosclerosis & Multiple genes & Hypo-, hypermethylation ${ }^{19,51}$ \\
\hline Colon & Multiple genes & Hypermethylation 20 & Homocysteinemia & Multiple genes & Hypomethylation ${ }^{52}$ \\
\hline Colorectal & L1 repeats & Hypomethylation ${ }^{35}$ & Vascular endothelium & eNOS & Hypomethylation ${ }^{53}$ \\
\hline Esophagus & $\mathrm{CDH} 1$ & Hypermethylation ${ }^{20}$ & \multicolumn{3}{|c|}{ Imprinting and pediatric syndromes } \\
\hline Liver & Multiple genes & Hypermethylation ${ }^{36}$ & UPD14 & $14 q 23-q 32$ & Imprinting ${ }^{57}$ \\
\hline Lung & $p 16, p 73$ & Hypermethylation ${ }^{20}$ & PHP, AHO, MAS & $20 \mathrm{q} 13.2$ & Imprinting ${ }^{58}$ \\
\hline Lymphoma & DAPK & Hypermethylation ${ }^{20}$ & Rett syndrome & MECP2 & Mutation $^{59}$ \\
\hline Myeloma & DAPK & Hypermethylation ${ }^{37}$ & ICF syndrome & DNMT3B & Mutation $^{60}$ \\
\hline Ovary & $B R C A 1$ & Hypermethylation ${ }^{38}$ & ATRX & ATRX & Chromatin structure ${ }^{61}$ \\
\hline Ovary & Sat2 & Hypomethylation ${ }^{39}$ & FraX & Triplet repeat & Silencing ${ }^{62}$ \\
\hline Pancreas & $A P C$ & Hypermethylation ${ }^{20}$ & FSHD & $3.3 \mathrm{~kb}$ repeat & Chromatin structure ${ }^{63}$ \\
\hline Pancreas & Multiple genes & Hypomethylation ${ }^{40}$ & \multicolumn{3}{|l|}{ Reproductive } \\
\hline Prostate & $B R C A 2$ & Hypermethylation ${ }^{20,41}$ & Ovarian teratoma & No paternal genome & Imprinting ${ }^{64}$ \\
\hline
\end{tabular}

Note: PWS = Prader-Willi syndrome; AS = Angelman syndrome; BWS = Beckwith-Weidemann syndrome; SRS = Silver-Russell syndrome; UPD14 = uniparental disomy 14; $\mathrm{PHP}=$ pseudohypoparathyroidism; $\mathrm{AHO}=$ Albright hereditary osteodystrophy; $\mathrm{MAS}=$ McCune-Albright syndrome; ICF $=$ immunodeficiency, centromeric instability and facial anomalies; ATRX $=\alpha$-thalassemia/mental retardation syndrome, $\mathrm{X}$-linked; FraX = Fragile X syndrome; FSHD = facioscapulohumeral muscular dystrophy, $\mathrm{CHM}=$ complete hydatidiform mole, $\mathrm{BiCHM}=$ familial biparental $\mathrm{CHM}$. 
In addition, epigenetic abnormalities, including imprinting defects, are likely responsible for the substantial embryonic losses (up to 98\%), placental hyperplasia and respiratory abnormalities observed in animal cloning models. ${ }^{75}$ This may be because, in cloning experiments, the nucleus of a somatic cell must be reprogrammed to the epigenetic state of an embryonic nucleus; genes expressed specifically in somatic cells must be silenced, while those required for embryonic development must be activated. The presence of epigenetic defects in the majority of cloned embryos indicates that the donated nucleus is not efficiently reprogrammed to the epigenetic state of the embryonic nucleus for which it is substituting. ${ }^{72,76}$ In contrast, a recent report showed that imprinting may be preserved in human embryonic stem cells, which suggests that these cells may be better candidates for therapeutic cloning. ${ }^{77} \mathrm{~A}$ thorough understanding of epigenetic mechanisms and errors is therefore required before ARTs can reach their true potential in assisted reproduction, animal cloning or the engineering of replacement tissue transplants in cases of Parkinson's and other diseases.

\section{Cancer and epigenetic therapies}

Cancer is a multistep process in which genetic and epigenetic errors accumulate and transform a normal cell into an invasive or metastatic tumour cell. Altered DNA methylation patterns change the expression of cancer-associated genes (Table I). DNA hypomethylation activates oncogenes and initiates chromosome instability ${ }^{78-80}$ whereas DNA hypermethylation initiates silencing of tumour suppressor genes. The incidence of hypermethylation, particularly in sporadic cancers, varies with respect to the gene involved and the tumour type in which the event occurs. For example, pI $6^{\text {INK } 4 A}$ promoter hypermethylation occurs in varying degrees $(9 \%-49 \%)$ in as many as 15 cancer types; in contrast, BRCA1 hypermethylation is primarily associated with $10 \%-20 \%$ of sporadic breast and ovarian cancers. ${ }^{20}$ These epigenetic changes can be used in the molecular diagnosis of a variety of cancers. ${ }^{81}$

To date, epigenetic therapies are few in number, but several are currently being studied in clinical trials or have been approved for specific cancer types. ${ }^{1,82,83}$ Nucleoside analogues such as azacitidine are incorporated into replicating DNA, inhibit methylation and reactivate previously silenced genes. ${ }^{84}$ Azacitidine has been effective in phase I clinical trials in treating myelodysplastic syndrome and leukemias characterized by gene hypermethylation. For example, $54 \%$ of patients with chronic myelogenous leukemia resistant to imatinib exhibited a complete or partial hematologic response, and $46 \%$ had a major or minor cytogenetic response to 5-aza-2'deoxycytidine. ${ }^{85}$ The antisense oligonucleotide MG98 that downregulates DNMTI is showing promising results in phase I clinical trials ${ }^{86}$ and in targeting solid tumours and renal cell cancer (www.methylgene.com/content.asp?node $=\mathrm{I} 4$ [accessed 2005 Dec 22]). Molecular analysis of biopsies of head and neck cancer following $\mathrm{MG}_{9} 8$ treatment revealed demethylation of 2 methylated tumour suppressor genes and methylation of an oncogene. Similarly, small molecules such as valproic acid that downregulate HDACs are being used to induce growth arrest and tumour cell death. Combination epigenetic therapies (demethylating agents plus HDAC inhibitors) or epigenetic therapy followed by conventional chemotherapy (or immunotherapy) may be more effective since they reactivate silenced genes, including tumour suppressor genes, resensitize drug-resistant cells to standard therapies and act synergistically to kill cancer cells. ${ }^{1,82,87}$ The key challenge for the future will be to limit toxic effects in normal cells and ensure that these novel drug effects reach critical target genes in tumour cells.

\section{Aging}

Both increases and decreases in DNA methylation are associated with the aging process, and evidence is accumulating that age-dependent methylation changes are involved in the development of neurologic disorders, autoimmunity and cancer in elderly people. ${ }^{88}$ Methylation changes that occur in an age-related manner may include the inactivation of cancerrelated genes. In some tissues, levels of methylated cytosines decrease in aging cells, and this demethylation may promote chromosomal instability and rearrangements, which increases the risk of neoplasia. ${ }^{88}$ In other tissues, such as the intestinal crypts, increased global hypermethylation may be the predisposing event that accounts for the increased risk of colon cancer with advancing age. ${ }^{89}$

\section{Immunity and related disorders}

The activation of the immune response involves stepwise epigenetic changes, which allow individual cells to mount a specific immune response that can be maintained over multiple cell generations. ${ }^{90,91}$ For example, shifts in both acetylation and methylation are required to coordinate DNA accessibility and permit recombination, thereby allowing cells to mount an immune response against a specific antigen. ${ }^{92}$ Recent reports suggest that loss of epigenetic control over this complex process contributes to autoimmune disease. Abnormal DNA methylation has been observed in patients with lupus whose $T$ cells exhibit decreased extracellular signal-regulated kinase pathway signalling, decreased methyltransferase activity and hypomethylated DNA. ${ }^{93}$ Disregulation of this pathway apparently leads to overexpression of methylation-sensitive genes such as the leukocyte function-associated factor (LFAI), which causes lupus-like autoimmunity. ${ }^{93,94}$ Interestingly, LFAI expression is also required for the development of arthritis, which raises the possibility that altered DNA methylation patterns may contribute to other diseases displaying idiopathic autoimmunity. ${ }^{95}$

\section{Neuropsychiatric disorders}

Recent reports have begun to address the role of epigenetic errors in the causation of complex adult psychiatric, autistic and neurodegenerative disorders (Table I).$^{96}$ Several reports have associated schizophrenia and mood disorders with DNA rearrangements that include the DNMT genes. ${ }^{96} D N M T I$ is selectively overexpressed in gamma-aminobutyric acid 
(GABA)-ergic interneurons of schizophrenic brains, ${ }^{97}$ whereas hypermethylation has been shown to repress expression of Reelin (a protein required for normal neurotransmission, memory formation and synaptic plasticity) in brain tissue from patients with schizophrenia and patients with bipolar illness and psychosis. ${ }^{98}$ In addition, the HDAC inhibitor valproic acid has been shown to prevent Reelin promoter hypermethylation in a mouse model of schizophrenia. ${ }^{99} \mathrm{~A}$ role for aberrant methylation mediated by folate levels has been suggested as a factor in Alzheimer's disease; however, there is contradictory evidence regarding hypomethylation and overexpression of the presenilin I gene that is involved in synaptic plasticity, long-term memory and neuronal survival. ${ }^{100,101}$ As well, some preliminary evidence supports a model that incorporates both genetic and epigenetic contributions in the causation of autism. ${ }^{102}$ Autism has been linked to the region on chromosome i5 that is responsible for Prader-Willi syndrome and Angelman syndrome. Findings at autopsy of brain tissue from patients with autism have revealed deficiency in $M E C P 2$ expression that appears to account for reduced expression of several relevant genes. ${ }^{103}$ These results suggest that $M E C P_{2}$ deficiency plays a role in chromosome organization in the developing brain in autism, Rett syndrome and several other neurodevelopmental disorders. ${ }^{104}$ There may be a role for epigenetics in the diagnosis and treatment of complex neuropsychiatric disorders in the future.

\section{Pediatric syndromes}

In addition to epigenetic alterations, specific mutations affecting components of the epigenetic pathway have been identified that are responsible for several syndromes: $D_{N M T_{3} B}$ in the ICF (immunodeficiency, centromeric instability and facial anomalies) syndrome, ${ }^{60} M E C P 2$ in Rett syndrome, ${ }^{105}$ ATR $X$ in ATR-X syndrome ( $\alpha$-thalassemia/mental retardation syndrome, $X$ linked ${ }^{61}$ and DNA repeats in facioscapulohumeral muscular dystrophy ${ }^{63}$ (Table I). In Rett syndrome, for example, $M E C P_{2}$ encodes a protein that binds to methylated DNA; mutations in this protein cause abnormal gene expression patterns within the first year of life. Girls with Rett syndrome display reduced brain growth, loss of developmental milestones and profound mental disabilities. ${ }^{105}$ Similarly, the ATR-X syndrome also includes severe developmental deficiencies due to loss of ATRX, a protein involved in maintaining the condensed, inactive state of DNA. ${ }^{61}$ Together, this constellation of clinical pediatric syndromes is associated with alterations in genes and chromosomal regions necessary for proper neurologic and physical development.

\section{The road ahead}

Our increased knowledge of epigenetic mechanisms over the last ro years is beginning to be translated into new approaches to molecular diagnosis and targeted treatments across the clinical spectrum. With the Human Genome Project completed, the Human Epigenome Project has been proposed and will generate genome-wide methylation maps. ${ }^{106}$
By examining both healthy and diseased tissues, specific genomic regions will be identified that are involved in development, tissue-specific expression, environmental susceptibility and pathogenesis. Use of these epigenetic maps will lead to epigenetic therapies for complex disorders across the clinical spectrum.

Our understanding of the role of epigenetic abnormalities in disease processes is still in its infancy. The primary goals over the next decade will include improving our understanding of the interplay between epigenetic mechanisms, gene expression and the environment, and moving from animal models to clinical trials of novel epigenetic therapies directed at a wide variety of diseases. By decreasing the risk of epigenetic instability that leads to disease and by correcting epigenetic abnormalities that predispose to diseases later in life, the promise for epigenetic therapies as an essential treatment option will be fulfilled.

From the EpiGenWestern Research Group at the Children's Health Research Institute (Rodenhiser, Mann) and the Departments of Biochemistry (Rodenhiser, Mann), Paediatrics (Rodenhiser), Oncology (Rodenhiser), and Obstetrics and Gynecology (Mann), University of Western Ontario, and the London Regional Cancer Program, London Health Sciences Centre (Rodenhiser), London, Ont.

Competing interests: None declared.

Contributors: Both authors shared in the writing of this article and revised the manuscript critically for important intellectual content, contributed to the concept and design of the manuscript and gave final approval of the version submitted for publication.

Acknowledgements: We thank our colleagues at the Children's Health Research Institute, the Translational Breast Cancer Research Unit, the London Regional Cancer Program and the EpiGenWestern Research Group, whose support and discussions led to our writing this review. We also thank Drs. Victor Han and Victoria Siu for critical review of this manuscript before submission.

Research by David Rodenhiser cited in this manuscript was funded by the Canadian Breast Cancer Research Alliance.

\section{REFERENCES}

I. Egger G, Liang G, Aparicio A, et al. Epigenetics in human disease and prospects for epigenetic therapy. Nature 2004;429:457-63.

2. Peterson CL, Laniel MA. Histones and histone modifications. Curr Biol 2004; I4: R546-5I.

3. Rountree MR, Bachman KE, Herman JG, et al. DNA methylation, chromatin inheritance, and cancer. Oncogene 2001;20:3156-65.

4. Feinberg AP, Tycko B. The history of cancer epigenetics. Nat Rev Cancer 2004;4: I43-53.

5. Avner P, Heard E. X-chromosome inactivation: counting, choice and initiation. Nat Rev Genet 200I;2:59-67.

6. Verona RI, Mann MR, Bartolomei MS. Genomic imprinting: intricacies of epigenetic regulation in clusters. Annu Rev Cell Dev Biol 2003;19:237-59.

7. Ehrlich M, Wang RY. 5-Methylcytosine in eukaryotic DNA. Science I981;212:1350-7.

8. Laird PW, Jaenisch R. DNA methylation and cancer. Hum Mol Genet 1994;3: I487-95.

9. Robertson KD. DNA methylation and chromatin - unraveling the tangled web. Oncogene 2002;21:536I-79.

Io. Espino PS, Drobic B, Dunn KL, et al. Histone modifications as a platform for cancer therapy. JCell Biochem 2005;94:1088-102.

II. Elgin SC, Grewal SI. Heterochromatin: Silence is golden. Curr Biol 2003; I3: R895-8.

I2. Hendrich B, Guy J, Ramsahoye B, et al. Closely related proteins $\mathrm{MBD}_{2}$ and $\mathrm{MBD}_{3}$ play distinctive but interacting roles in mouse development. Genes Dev 200I;15:710-23.

13. Ehrenhofer-Murray AE. Chromatin dynamics at DNA replication, transcription and repair. Eur J Biochem 2004;271:2335-49.

I4. Luch A. Nature and nurture - lessons from chemical carcinogenesis. Nat Rev Cancer 2005;5:113-25.

15. Sutherland JE, Costa M. Epigenetics and the environment. Ann N Y Acad Sci 2003; 983:15I-6o. 
I6. Ulrey CL, Liu L, Andrews LG, et al. The impact of metabolism on DNA methylation. Hum Mol Genet 2005; I4(Suppl I):RI39-47.

17. Curtin K, Bigler J, Slattery ML, et al. MTHFR C677T and AI298C polymorphisms diet, estrogen, and risk of colon cancer. Cancer Epidemiol Biomarkers Prev 2004; I3:285-92.

18. Waterland RA, Jirtle RL. Early nutrition, epigenetic changes at transposons and imprinted genes, and enhanced susceptibility to adult chronic diseases. Nutrition 2004;20:63-8.

19. Zaina S, Lindholm MW, Lund G. Nutrition and aberrant DNA methylation patterns in atherosclerosis: More than just hyperhomocysteinemia? J Nutr 2005;135:5-8.

20. Esteller M, Corn PG, Baylin SB, et al. A gene hypermethylation profile of human cancer. Cancer Res 2001;6r:3225-9.

2I. Friso S, Choi SW. Gene-nutrient interactions and DNA methylation. J Nutr 2002; I32:2382S-7S.

22. Hiltunen MO, Turunen MP, Hakkinen TP, et al. DNA hypomethylation and methyltransferase expression in atherosclerotic lesions. Vasc Med 2002;7:5-II.

23. Rossman TG. Mechanism of arsenic carcinogenesis: an integrated approach. $\mathrm{Mu}$ tat Res 2003;533:37-65.

24. Ergul E, Sazci A, Utkan Z, et al. Polymorphisms in the MTHFR gene are associated with breast cancer. Tumour Biol 2003;24:286-90.

25. Semenza JC, Delfino RJ, Ziogas A, et al. Breast cancer risk and methylenetetrahydrofolate reductase polymorphism. Breast Cancer Res Treat 2003;77:217-23.

26. Le Marchand L, Haiman CA, Wilkens LR, et al. MTHFR polymorphisms, diet, HRT, and breast cancer risk: the multiethnic cohort study. Cancer Epidemiol Biomarkers Prev 2004;13:207I-7.

27. Morgan, HD, Santos F, Green K, et al. Epigenetic reprogramming in mammals. Hum Mol Genet 2005; I4(Suppl I):R47-58.

28. Uhlmann K, Rohde K, Zeller C, et al. Distinct methylation profiles of glioma subtypes. Int J Cancer 2003;106:52-9.

29. Gao Y, Guan M, Su B, et al. Hypermethylation of the RASSFiA gene in gliomas. Clin Chim Acta 2004;349:173-9.

30. Bello MJ, Alonso ME, Aminoso C, et al. Hypermethylation of the DNA repair gene MGMT: association with TP53 G:C to A:T transitions in a series of 469 nervous system tumors. Mutat Res 2004;554:23-32.

3I. Mancini DN, Rodenhiser DI, Ainsworth PJ, et al. CpG methylation within the 5 regulatory region of the BRCAI gene is tumor specific and includes a putative CREB binding site. Oncogene I998; I6:Ir6I-9.

32. Szyf M, Pakneshan P, Rabbani SA. DNA methylation and breast cancer. Biochem Pharmacol 2004;68:1187-97.

33. Widschwendter M, Jones PA. DNA methylation and breast carcinogenesis. Oncogene 2002;21:5462-82.

34. Lea JS, Coleman R, Kurien A, et al. Aberrant pi6 methylation is a biomarker for tobacco exposure in cervical squamous cell carcinogenesis. Am J Obstet Gynecol 2004;190:674-9.

35. Suter CM, Martin DI, Ward RL. Hypomethylation of LI retrotransposons in colorectal cancer and adjacent normal tissue. Int J Colorectal Dis 2004;19:95-I0I.

36. De Zhu J. The altered DNA methylation pattern and its implications in liver cancer. Cell Res 2005;15:272-80.

37. Chim CS, Kwong YL, Fung TK, et al. Methylation profiling in multiple myeloma. Leuk Res 2004;28:379-85.

38. Esteller M, Silva JM, Dominquez G, et al. Promoter hypermethylation and BRCAI inactivation in sporadic breast and ovarian tumors. J Natl Cancer Inst 2000;92 564-9.

39. Widschwendter M., Jiang G, Woods C, et al. DNA hypomethylation and ovarian cancer biology. Cancer Res 2004;64:4472-80.

40. Sato N, Maitra A, Fukushima N, et al. Frequent hypomethylation of multiple genes overexpressed in pancreatic ductal adenocarcinoma. Cancer Res 2003;63:4158-66.

4I. Li LC, Okino ST, Dahiya R. DNA methylation in prostate cancer. Biochim Biophys Acta 2004;1704:87-IO2.

42. Kurmasheva RT, Peterson CA, Parham DM, et al. Upstream CpG island methylation of the $\mathrm{PAX}_{3}$ gene in human rhabdomyosarcomas. Pediatr Blood Cancer 2005; 44:328-37.

43. Oshimo Y, Nakayama H, Ito R, et al. Promoter methylation of cyclin $\mathrm{D}_{2}$ gene in gastric carcinoma. Int J Oncol 2003;23:1663-70.

44. Ye L, Li X, Kong X, et al. Hypomethylation in the promoter region of POMC gene correlates with ectopic overexpression in thymic carcinoids. J Endocrinol 2005 I85:337-43

45. Nakagawa T, Kanai Y, Ushijima S, et al. DNA hypomethylation on pericentromeric satellite regions significantly correlates with loss of heterozygosity on chromosome 9 in urothelial carcinomas. J Urol 2005;173:243-6.

46. Sharma RP. Schizophrenia, epigenetics and ligand-activated nuclear receptors: a framework for chromatin therapeutics. Schizophr Res 2005;72:79-90.

47. Costa E, Chen Y, Davis J, et al. REELIN and schizophrenia: a disease at the interface of the genome and the epigenome. Mol Interv 2002;2:47-57.

48. Petronis A. Epigenetics and bipolar disorder: new opportunities and challenges. Am J Med Genet C Semin Med Genet 2003;123:65-75.

49. Levenson JM, Sweatt JD. Epigenetic mechanisms in memory formation. Nat Rev Neurosci 2005;6:108-18.

50. Sekigawa I, Okada M, Ogasawara H, et al. DNA methylation in systemic lupus erythematosus. Lupus 2003;12:79-85.

5I. Lund G, Anderson L, Lauria M, et al. DNA methylation polymorphisms precede any histological sign of atherosclerosis in mice lacking apolipoprotein E. J Biol Chem 2004;279:29147-54.

52. Lievers KJ, Kluijtmans LA, Blom HJ. Genetics of hyperhomocysteinaemia in car- diovascular disease. Ann Clin Biochem 2003;40:46-59.

53. Chan Y, Fish JE, D'Abreo C, et al. The cell-specific expression of endothelial nitricoxide synthase: a role for DNA methylation. J Biol Chem 2004;279:35087-100.

54. Nicholls RD, Knepper JL. Genome organization, function, and imprinting in Prader-Willi and Angelman syndromes. Annu Rev Genomics Hum Genet 200I;2: I53-75.

55. Weksberg R, Smith AC, Squire J, et al. Beckwith-Wiedemann syndrome demonstrates a role for epigenetic control of normal development. Hum Mol Genet 2003; I2(Suppl I):R6I-8.

56. Hitchins MP, Stanier P, Preece MA, et al. Silver-Russell syndrome: a dissection of the genetic aetiology and candidate chromosomal regions. J Med Genet 200I; 38:810-9.

57. Kamnasaran D, Cox DW. Current status of human chromosome I4. J Med Genet 2002;39:8I-90.

58. Beaudet AL. Complex imprinting. Nat Genet 2004;36:793-5.

59. Van den Veyver IB, Zoghbi HY. Mutations in the gene encoding methyl-CpGbinding protein 2 cause Rett syndrome. Brain Dev 200I;23(Suppl I):SI47-5I.

6o. Ehrlich $M$. The ICF syndrome, a DNA methyltransferase $3 \mathrm{~B}$ deficiency and immunodeficiency disease. Clin Immunol 2003;109:17-28.

6r. Gibbons RJ, McDowell TL, Raman S, et al. Mutations in ATRX, encoding a SWI/ SNF-like protein, cause diverse changes in the pattern of DNA methylation. Nat Genet 2000;24:368-71.

62. Tassone F, Hagerman PJ. Expression of the FMRI gene. Cytogenet Genome Res 2003;100:124-8.

63. Tupler R, Gabellini D. Molecular basis of facioscapulohumeral muscular dystrophy. Cell Mol Life Sci 2004;61:557-66.

64. Kuno N, Kadomatsu K, Nakamura M, et al. Mature ovarian cystic teratoma with a highly differentiated homunculus: a case report. Birth Defects Res A Clin Mol Teratol 2004;70(I):40-6

65. Devriendt K. Hydatidiform mole and triploidy: the role of genomic imprinting in placental development. Hum Reprod Update 2005;II:137-42.

66. Liu L, Wylie RC, Andrews LG, et al. Aging, cancer and nutrition: the DNA methylation connection. Mech Ageing Dev 2003;124:989-98.

67. El-Maarri O, Seoud M, Coullin P, et al. Maternal alleles acquiring paternal methylation patterns in biparental complete hydatidiform moles. Hum Mol Genet 2003; I2:I405-I3.

68. Van Dijk M, Mulders J, Poutsma A, et al. Maternal segregation of the Dutch preeclampsia locus at roq22 with a new member of the winged helix gene family. Nat Genet 2005;37:514-9.

69. McDonald SD, Murphy K, Beyene J, et al. Perinatel outcomes of singleton pregnancies achieved by in vitro fertilization: a systematic review and meta-analysis. $\mathrm{JOb}$ stet Gynaecol Can 2005;27:449-59.

70. Niemitz EL, Feinberg AP. Epigenetics and assisted reproductive technology: a call for investigation. Am J Hum Genet 2004;74:599-6o9.

71. Gicquel C, Gaston V, Mandelbaum J, et al. In vitro fertilization may increase the risk of Beckwith-Wiedemann syndrome related to the abnormal imprinting of the KCNIOT gene. Am J Hum Genet 2003;72(5):1338-4I.

72. Mann MR, Chung YG, Nolen LD, et al. Disruption of imprinted gene methylation and expression in cloned preimplantation stage mouse embryos. Biol Reprod 2003;69:902-I4

73. Young LE, Fernandez K, McEvoy TG, et al. Epigenetic change in $\mathrm{IGF}_{2} \mathrm{R}$ is associated with fetal overgrowth after sheep embryo culture. Nat Genet 200I;27:153-4.

74. Maher ER, Afnan M, Barratt CL. Epigenetic risks related to assisted reproductive technologies: Epigenetics, imprinting, ART and icebergs? Hum Reprod 2003; I8: 2508-II.

75. Alberio R, Campbell KH. Epigenetics and nuclear transfer. Lancet 2003;36r: I239-40.

76. Nolen LD, Goa S, Han Z, et al. X chromosome reactivation and regulation in cloned embryos. Dev Biol 2005;279:525-40.

77. Rugg-Gunn PJ, Ferguson-Smith AC, Pedersen RA. Epigenetic status of human embryonic stem cells. Nat Genet 2005;37:585-7.

78. Kazazian HH Jr. Mobile elements: drivers of genome evolution. Science 2004;303: I626-32.

79. Narayan A, Zhang XY, Marrogi A, et al. Hypomethylation of pericentromeric DNA in breast adenocarcinomas. Int J Cancer $1998 ; 77: 833-8$.

8o. Gaudet F, Hodgson JG, Eden A, et al. Induction of tumors in mice by genomic hypomethylation. Science 2003;300:489-92.

8I. Cottrell SE. Molecular diagnostic applications of DNA methylation technology. Clin Biochem 2004;37:595-604.

82. Balch C, Mongomery JS, Paik HI, et al. New anti-cancer strategies: epigenetic therapies and biomarkers. Front Biosci 2005;10:1897-931.

83. Laird PW. Cancer epigenetics. Hum Mol Genet 2005;I4(Suppl I):R65-76.

84. Esteller M. DNA methylation and cancer therapy: new developments and expectations. Curr Opin Oncol 2005;17:55-6o.

85. Issa JP, Kantarjian HM, Kirkpatrick P. Azacitidine. Nat Rev Drug Discov 2005;4: 275-6.

86. Davis AJ, Gelmon KA, Siu LL, et al. Phase I and pharmacologic study of the human DNA methyltransferase antisense oligodeoxynucleotide $\mathrm{MG}_{9} 8$ given as a $2 \mathrm{I}$-day continuous infusion every 4 weeks. Invest New Drugs 2003;21:85-97.

87. Mongan NP, Gudas LJ. Valproic acid, in combination with all-trans retinoic acid and 5-aza-2'-deoxycytidine, restores expression of silenced RARbeta2 in breast cancer cells. Mol Cancer Ther 2005;4:477-86.

88. Richardson B. Impact of aging on DNA methylation. Ageing Res Rev 2003;2: $245-6$ I. 
89. Rashid A, Issa JP. CpG island methylation in gastroenterologic neoplasia: a maturing field. Gastroenterology 2004;127:1578-88.

9o. Fitzpatrick DR, Wilson CB. Methylation and demethylation in the regulation of genes, cells, and responses in the immune system. Clin Immunol 2003; ;09: 37-45.

9I. Bergman Y, Cedar H. A stepwise epigenetic process controls immunoglobulin allelic exclusion. Nat Rev Immunol 2004;4:753-6I.

92. Wilson CB, Makar KW, Shnyreva M, et al. DNA methylation and the expanding epigenetics of T cell lineage commitment. Semin Immunol 2005;17:105-I9.

93. Oelke K, Richardson B. Decreased T cell ERK pathway signaling may contribute to the development of lupus through effects on DNA methylation and gene expression. Int Rev Immunol 2004;23:315-31.

94. Richardson B. DNA methylation and autoimmune disease. Clin Immunol 2003 I09:72-9.

95. Watts GM, Beurskens FJ, Martin-Padura I, et al. Manifestations of inflammatory arthritis are critically dependent on LFA-I. J Immunol 2005;174:3668-75.

96. Abdolmaleky HM, Smith CL, Faraone SV, et al. Methylomics in psychiatry: Modulation of gene-environment interactions may be through DNA methylation. Am Med Genet B Neuropsychiatr Genet 2004;127:5I-9.

97. Veldic M, Guidotti A, Maloku E, et al. In psychosis, cortical interneurons overexpress DNA-methyltransferase I. Proc Natl Acad Sci U S A 2005;102:2152-7.

98. Chen Y, Sharma RP, Costa RH, et al. On the epigenetic regulation of the human reelin promoter. Nucleic Acids Res 2002;30:2930-9.

99. Tremolizzo L, Doueiri MS, Dong E, et al. Valproate corrects the schizophrenia-like epigenetic behavioral modifications induced by methionine in mice. Biol Psychiatry 2005;57:500-9
Ioo. Fuso A, Seminara L, Cavallaro RA., et al. S-adenosylmethionine/homocysteine cycle alterations modify DNA methylation status with consequent deregulation of PSi and BACE and beta-amyloid production. Mol Cell Neurosci 2005;28:195-204.

IoI. Mulder C, Schoonenboom NS, Jansen EE, et al. The transmethylation cycle in the brain of Alzheimer patients. Neurosci Lett 2005;386:69-7I.

I02. Jiang YH, Sahoo T, Michaelis RC, et al. A mixed epigenetic/genetic model for oligogenic inheritance of autism with a limited role for UBE3A. Am J Med Genet A 2004;I3I:I-IO.

I03. Samaco RC, Hogart A, LaSalle JM. Epigenetic overlap in autism-spectrum neurodevelopmental disorders: MECP2 deficiency causes reduced expression of $\mathrm{UBE}_{3} \mathrm{~A}$ and GABRB3. Hum Mol Genet 2005;14:483-92.

I04. Thatcher KN, Peddada S, Yasui DH, et al. Homologous pairing of I5qII-I3 imprinted domains in brain is developmentally regulated but deficient in Rett and autism samples. Hum Mol Genet 2005;I4:785-97.

I05. Kriaucionis S, Bird A. DNA methylation and Rett syndrome. Hum Mol Genet 2003 I2(Suppl 2):R22I-7.

Io6. Jones PA, Martienssen R. A blueprint for a Human Epigenome Project: the AACR Human Epigenome Workshop. Cancer Res 2005;65(24):II24I-6.

Correspondence to: Dr. David Rodenhiser, Associate Professor, Department of Paediatrics, University of Western Ontario, Rm. A4-I34, Victoria Research Tower, 790 Commissioners Rd. E, London ON N6A4L6; fax 519 685-86I6; drodenhi@uwo.ca

\section{$2006 \quad P$ I S C H E D U L E}

\section{P HYSICIAN \\ MA N A G E R I NSTITUTE}

\section{A five level credit program exclusively for physicians designed to develop superior leadership and management skills}

Approved for RCPSC, CFPC, CCHSE credits

\section{In-house PMI}

A practical, cost effective and focused training opportunity held on-site for medical leaders and managers

\section{For information:}

tel $800663-7336$ or $613731-8610$

x2319 (PMI) or x2261 (In-house PMI)

professional_development@cma.ca

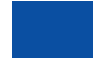 \\ PMI I/II}

Mar. 5-7/Mar. 8-10

Apr. 2-4/Apr. 5-7

June 11-13/June 14-16

Sept. 24-26/Sept. 27-29

Victoria, BC

Toronto, ON

Ottawa, ON

Calgary, AB

\section{PMI III/IV}

Apr. 30-May 2/May 3-5 Niagara-on-the-Lake, ON

Nov. 5-7/Nov. 8-10

Vancouver, BC
PMI V

Oct. 20-22 Vancouver, BC 